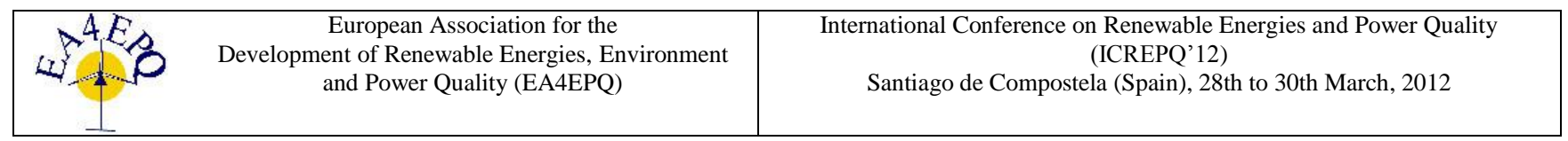

\title{
Application of Trigeneration to a Multi-Unit Residential Building in Canada
}

\author{
D. Allaire-Tanguay ${ }^{1}$, N. Galanis ${ }^{1}$ and R. Sunyé ${ }^{2}$ \\ ${ }^{1}$ Department of Mechanical Engineering \\ Université de Sherbrooke \\ 2500 boul Université, Sherbrooke QC, J1K2R1 (Canada) \\ Phone/Fax number: 0018198217144 \\ e-mail: Nicolas.Galanis@usherbrooke.ca, Dominique.Allaire.Tanguay@USherbrooke.ca \\ ${ }^{2}$ Canmet ENERGY, Natural Resources Canada \\ 1615 boul Lionel-Boulet, P.O. Box 4800, Varennes QC, Canada \\ Phone: 001450 6527822, email: Roberto.Sunye@ RNCan-NRCan.gc.ca
}

\begin{abstract}
This paper presents the model developed to compare a trigeneration system to existing heating, cooling and electricity generation methods. The archetype of a typical 13 storey multi-unit residential building has been simulated in TRNSYS with an array of commercially available cogeneration units. These units provide the required heating to the building through water storage and produce electricity as a subsidiary. During cooling periods heat from these units fuels a combination of absorption machines modelled especially for this application. Results show a reduction of primary energy consumption compared to an actual scenario. Further analysis of the controls and storage size would be required to optimize this system.
\end{abstract}

\section{Key words}

Trigeneration; Combined Cooling Heating and Power; Cogeneration; Absorption cooling.

\section{Introduction}

Energy demand increases continuously creating pressure on the price of fossil fuels which still constitute the most important primary energy source. Their conversion to electricity or any other useful form involves the transformation of their chemical energy into thermal energy through combustion and is therefore governed by the second law of thermodynamics; as a result the efficiency of these processes is limited to a maximum of approximately $50 \%$. Furthermore, the combustion of fossil fuels creates well documented environmental problems. Considerable efforts are therefore made to increase the contribution of clean renewable energy sources and to improve the overall efficiency of fossil fuel plants. The latter objective can be achieved by converting the waste heat into electricity using appropriate working fluids for these medium to low temperature sources (organic Rankine cycles, etc.) or to supply a matching thermal demand (industrial process, etc.). While the first of these approaches is realistically only applicable to large power plants the second one, known as cogeneration, can be implemented in individual buildings. It is particularly interesting if the thermal demand varies more or less proportionally to the electricity demand and it improves the efficiency of fossil fuel conversion systems while diminishing the need for central peak demand plants which operate for short periods of time. However, in the case of buildings heating is only required during winter. To remedy for this lack of uniform heating demand, it is possible to add an absorption machine to generate cooling during summer: this system which uses a fossil fuel to generate electricity, heating and cooling is known as a trigeneration system.

Trigeneration is a rather new subject and relatively few aspects of it have been studied in detail. Some studies have tested prototype systems [1-4] with encouraging results especially for larger systems. Others have evaluated its performance and economical feasibility based on assumed component efficiencies [5-8] and indicate that trigeneration performs better by following the heat demand during the cold season and the electricity prices during the warm season. Only one study [9] has assessed the hourly interaction of the different components of the system for a $210 \mathrm{~m}^{2}$ household but used a simplified model for the absorption cooler based on one particular machine. The present study developed a general model for the absorption machine and obtained annual performance predictions for a trigeneration system providing heating, cooling and domestic hot water to a 13 storey multi-unit residential building (MURB). The study, realized with the TRNSYS software [10] for a typical meteorological year, focuses on the interactions between the different components, analyses the overall performance of the system for different locations in Canada and compares it with that of traditional systems. 


\section{System Description and Model}

The system under investigation (Figure 1) is made of standard natural gas fired internal combustion cogeneration units [11] that produce electricity transferred to the grid and heat. This heat is extracted from both the cooling fluid and the exhaust gases by water whose temperature does not exceed $90^{\circ} \mathrm{C}$. Various combinations of 70 and $140 \mathrm{kWe}$ units are used depending on the heating load; their electric and global efficiencies are respectively $35 \%$ and $91 \%$. To ensure a smooth operation of the system, a $120 \mathrm{~m}^{3}$ hot water storage tank is used and its top layer is kept at temperatures between 77 and $85^{\circ} \mathrm{C}$. From this tank, water can be drawn to meet the various demands by a variable flow pump. The building and the domestic hot water are indirectly heated by heat exchangers with a fixed effectiveness of $80 \%$. To produce cooling, the hot water is provided to an array of $100 \mathrm{~kW}$ ammonia-water water-cooled absorption machines. Since cooling operation times are short and difficult to predict, a cold water storage tank temporizes the use of the absorption machines; it also allows the use of smaller equipment and hence reduces the investment cost. The 13 storeys building is based on an archetype MURB [12] and is simulated with the TRNSYS multi-zone building (type 56). To shorten simulation times the building is simulated with only 3 storeys (ground, middle, top); the energy demands of the middle floor are multiplied by 11 to obtain the total energy consumption of the MURB. Each storey is divided into 5 zones: North, South, East, West and a central unheated corridor. Each zone has a specific and limited heating and cooling installed power designed to meet the required load $98 \%$ of the time.

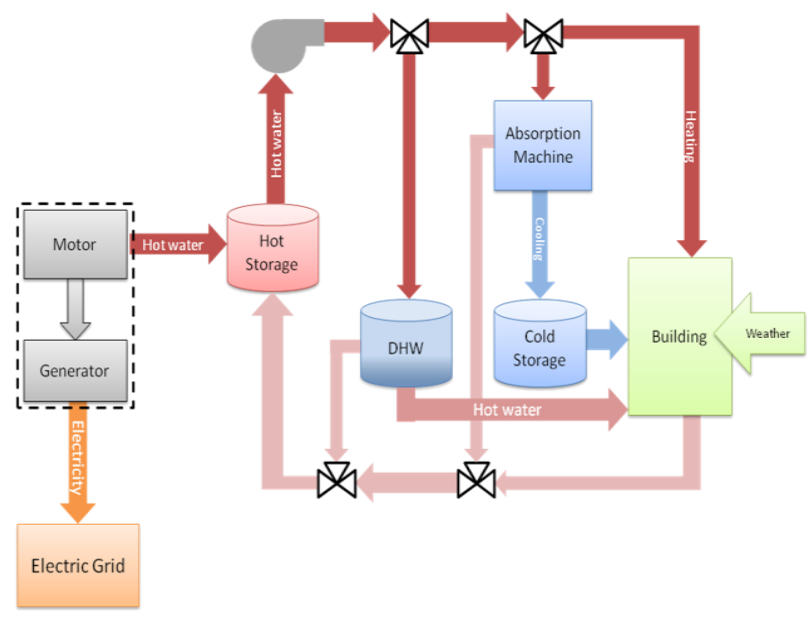

Fig. 1 Schematic representation of the trigeneration system

Based on published recommendations $[5,6]$ the operation of the cogeneration units during the cold season is controlled by the quantity of heat necessary to satisfy the heating load of the MURB. On the other hand, during the hot season the operation of the cogeneration units is controlled by the heat demand of the absorption cooler which depends on the cooling load of the building. Specifically an appropriate number of cogeneration units are turned on to ensure that the return temperature of the coolant entering the internal combustion engines does not fall below $60{ }^{\circ} \mathrm{C}$. The corresponding mass flowrate is adjusted to maintain the temperature of the coolant at the engine exit at or below $90{ }^{\circ} \mathrm{C}$. These two values are the minimum and maximum temperatures of the bottom and top layers of the stratified hot storage tank.

The single effect absorption cooler (Figure 2) uses an ammonia-water mixture and includes a rectifier and two internal heat exchangers. The first (SHX) is used to preheat the strong solution entering the desorber thus reducing the heat input to this unit; the second (RHX) is used to subcool the refrigerant leaving the condenser thus increasing the heat per unit flowrate which can be extracted at the evaporator. For the simulation the desorber is subdivided into three superimposed parts (Figure 3). In the lower part, the boiler, heat from the hot storage (cf. Figure 1) is used to evaporate part of the liquid ammonia-water mixture supplied by the middle part, the purifier; the remaining liquid is directed to the solution heat exchanger SHX. In the purifier the vapour from the boiler is mixed with the strong solution from SHX and the liquid from the top part, the exhauster; the resulting liquid and vapour are fed to the boiler and exhauster respectively. In the exhauster the vapour from the purifier is mixed with the reflux from the rectifier and the resulting liquid and vapour are fed to the purifier and rectifier respectively. Gravity ensures the transfer of liquid between these three parts. Heat transfer to or from the working fluid takes place in the condenser, the evaporator, the absorber, the boiler and the rectifier.

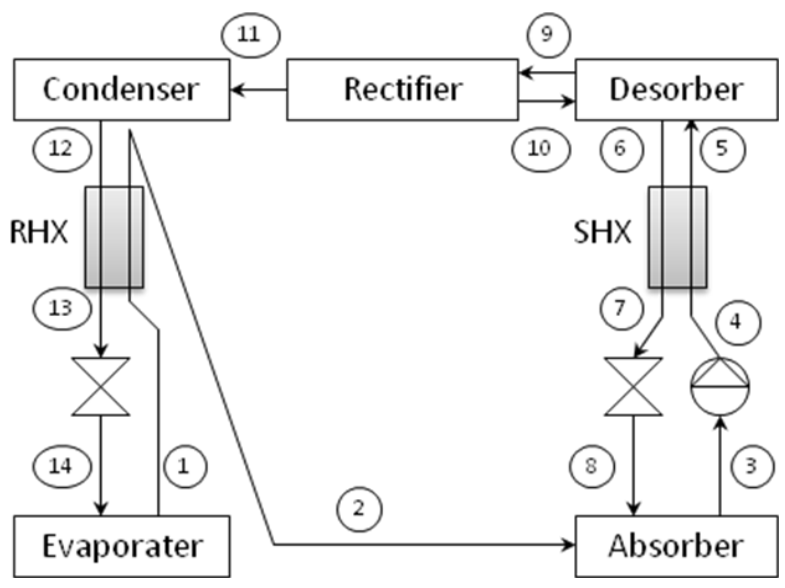

Fig. 2 Schematic representation of the absorption cooler

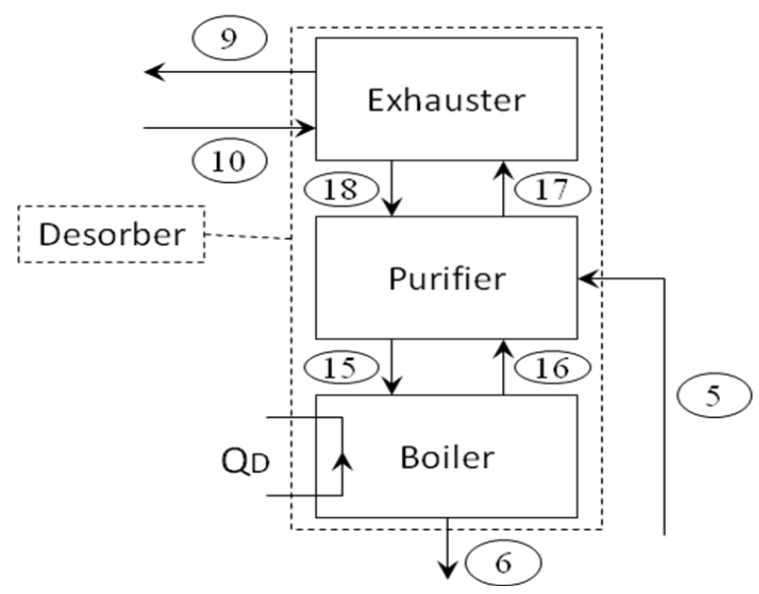

Fig. 3 Details of the desorber 
The assumptions used to model the performance of the entire system are:

- Each component is an open system without mass accumulation;

- The cogeneration units and the absorption machines operate under steady state conditions at each timestep;

- Pressure losses are neglected except in the expansion valves of the absorption cooler which are isenthalpic;

- Heat losses from the pipes connecting the individual components and all the heat exchangers are neglected; however they are taken into account in the case of the storage reservoirs;

- The refrigerant in the condenser and evaporator of the absorption cooler is pure ammonia;

- The fluid at 3, 6, 10,12,15, 18 is saturated liquid;

- The fluid at 1, 9, 11, 16, 17 is saturated vapour;

- Equality of the temperature of the fluids leaving the boiler $\left(\mathrm{T}_{6}=\mathrm{T}_{16}\right)$, the exhauster $\left(\mathrm{T}_{9}=\mathrm{T}_{18}\right)$ and the rectifier $\left(\mathrm{T}_{10}=\mathrm{T}_{11}\right)$;

- The pump of the absorption cooler has a fixed efficiency while the power of the three pumps in the different loops of the trigeneration system varies proportionally to the cube of their flowrate.

The model of the absorption cooler is based on the conservation equations for each component of the system (mass for each substance of the working fluid and energy), the expression of the heat transfer rate for each heat exchanger (in terms of their thermal capacitance UA and the corresponding logarithmic mean temperature difference or in terms of their effectiveness) and on the relation between the thermodynamic properties (concentration of ammonia, pressure, temperature, quality of vapour-liquid mixture, enthalpy, etc.) at each state. Including the above assumptions the model of the absorption cooler involves 134 equations and 146 variables. This system of coupled non-linear equations was implemented in EES [13] and validated by comparison with results in previous studies [14]. It was then used independently of TRNSYS to determine an appropriate design by fixing eight variables and by varying the temperature of the working fluid at the outlet of the four external heat exchangers. The combination of these four internal temperatures which results in a high value of the coefficient of performance (COP) and a low value of the total thermal conductance $\left(\mathrm{UA}_{\mathrm{tot}}\right)$ of the 6 heat exchangers was chosen as the design point for the absorption machine. The resulting thermal conductance of each of the six heat exchangers was then fixed and the model of the absorption machine was coupled with the TRNSYS models of the other components of the trigeneration system (building, storage reservoirs, pumps, etc). Since the cooling load of the building as well as the temperature of the external fluids vary with time, the model predicts the yearly offdesign performance of the absorption machine.

\section{Results and Discussion}

The design parameters of the absorption cooler were determined by fixing the temperature of the external water at the outlet of the evaporator $\left(7^{\circ} \mathrm{C}\right)$ as well as at the inlet of the absorber $\left(15^{\circ} \mathrm{C}\right)$, the condenser $\left(15^{\circ} \mathrm{C}\right)$ and the desorber $\left(77^{\circ} \mathrm{C}\right)$; furthermore the pump efficiency $(90 \%)$, the effectiveness of the two internal heat exchangers $(80 \%)$ and the cooling capacity $\mathrm{Q}_{\mathrm{E}}$ were also kept constant. It should be noted that $\mathrm{Q}_{\mathrm{E}}$ does not influence the thermodynamic properties of the working fluid or the ratio of the mass flowrates in the external heat exchangers; however the value of each mass flowrate and each thermal conductance varies proportionally to $\mathrm{Q}_{\mathrm{E}}$. The temperature of the working fluid at the outlet of the external heat exchangers $\left(T_{1}, T_{3}, T_{6}, T_{12}\right)$ was then varied and the other 134 variables in the model of the absorption cooler were determined by solving it with EES. It was then possible to evaluate the COP of the system and its total thermal conductance. For a well-performing and economical cooling system the COP should be high and the total thermal conductance low. We therefore chose the ratio VD between the square of the COP and the total thermal conductance as the indicator for the determination of a good cooling system and analyzed the effect of the above mentioned eight design parameters on its value. Figure 4 illustrates some of these results, specifically the effects of the evaporation temperature $T_{1}$. As expected the COP increases monotonically with $\mathrm{T}_{1}$ but at the same time the temperature difference between the two fluids in the evaporator diminishes and therefore the corresponding thermal conductance $\mathrm{UA}_{\mathrm{e}}$ increases dramatically; the total thermal conductance behaves similarly and as a result the value of the performance indicator VD reaches a maximum for $\mathrm{T}_{1} \approx 275 \mathrm{~K}$. Sensitivity analyses carried out by varying some of the other design parameters showed that this optimum value of $\mathrm{T}_{1}$ is essentially independent of the other design parameters. Similar calculations for the other design parameters were performed and the chosen combination as well as the resulting values of some variables defining the size of the absorption cooler are specified in Table 1.

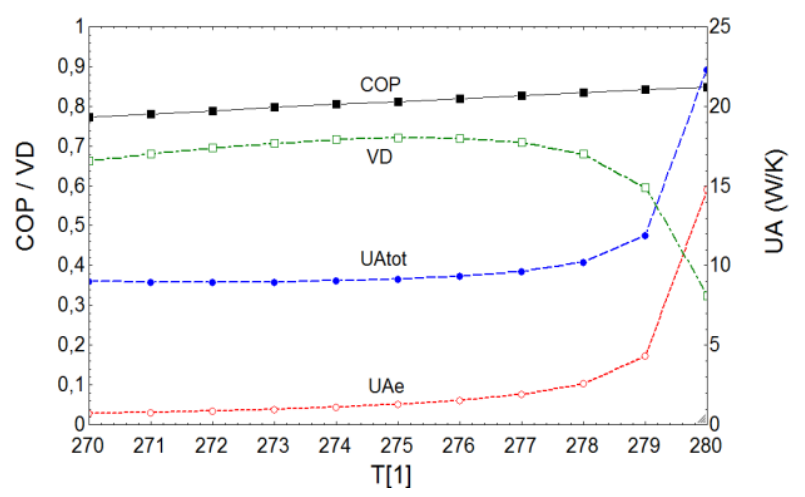

Fig. 4 Effects of the evaporation temperature on the performance of a $3 \mathrm{~kW}$ absorption cooler

Table 1 Design parameters of a $3 \mathrm{~kW}$ absorption cooler (m in kg/s, Y in $\mathrm{g} \mathrm{NH3/g,} \mathrm{UA} \mathrm{and} \mathrm{mcp} \mathrm{in} \mathrm{kW} / \mathrm{K}$ )

\begin{tabular}{|c|c|c|}
\hline $\mathrm{P} 1=3.034$ bar & $\dot{\mathrm{m}} 1=2.445$ & $Y 1=1$ \\
\hline $\mathrm{P} 3=3.034 \mathrm{bar}$ & $\dot{\mathrm{m}} 3=12.460$ & $Y 3=0.565$ \\
\hline $\mathrm{P} 6=8.729$ bar & $\dot{\mathrm{m}} 6=10.015$ & $\mathrm{Y} 6=0.434$ \\
\hline $\mathrm{P} 12=8.729 \mathrm{bar}$ & $\dot{\mathrm{m}} 12=2.445$ & $\mathrm{Y} 12=1$ \\
\hline $\mathrm{COP}=0.804$ & UAtot $=2.303$ & UAabs $=0.696$ \\
\hline UAev $=0.464$ & UAdes $=0.431$ & UArhx $=0.034$ \\
\hline UAcon $=0.328$ & UAshx $=0.35$ & $(\dot{m} \mathrm{cp}) \mathrm{abs}=0.84$ \\
\hline$(\dot{m} \mathrm{cp}) \operatorname{con}=3.26$ & (m)p)des $=0.13$ & $(\dot{\mathrm{m} c p}) \mathrm{ev}=1.06$ \\
\hline
\end{tabular}


The EES model of a $100 \mathrm{~kW}$ absorption cooler was then coupled with the TRNSYS model of the other system components (see Fig. 1). The performance of this trigeneration system was simulated for an entire year using typical hourly meteorological data (ambient temperature, solar radiation, relative humidity) for the city of Montreal, Canada [15]. For this simulation the thermal conductance values and the (mcp) products for the four external fluids identified in Table 1 were fixed while the temperature of the external fluids entering the corresponding heat exchangers (condenser, evaporator, absorber, boiler) were supplied at each timestep by other components of the TRNSYS model. The simultaneous solution of the differential and algebraic equations modeling all the components of the system gives, at each timestep, the value of all the variables (number of motor-generator units in operation, number of absorption coolers in operation, mass flowrate in each branch of the system, temperature at each level of the stratified storage reservoirs, state of the working fluid at each point of Figures 2 and 3, heating and/or cooling load for each zone of the building, etc.) describing the operation of the trigeneration system.

Figure 5 shows some results of the yearly simulation and describes the off-design performance of the absorption cooler. We note that cooling is required during approximately 8 months (sporadically in April and November but more or less continuously from May to October albeit with variable load). The temperature of the water supplied by the hot reservoir to the desorber (TD_in) varies between 80 and $90{ }^{\circ} \mathrm{C}$ while that of the water entering the condenser (TC_in) shows a typical seasonal behaviour with an amplitude of approximately $5^{\circ} \mathrm{C}$. The temperature of the water leaving the boiler (TD_out) and returning to the hot storage is always close to $60^{\circ} \mathrm{C}$. Finally, at the evaporator the temperature of the water entering (TE_in) and leaving (TE_out) is essentially constant, equal to approximately 20 and $7{ }^{\circ} \mathrm{C}$ respectively. As a result of these operating conditions the COP of the absorption cooler varies very little $(0.78 \pm 0.01)$. However it should be noticed that its value is always slightly lower than the design value which is equal to 0.804 (see Table 1). This result is principally attributed to the fact that the temperature of the external fluids entering the four external heat exchangers is slightly different from the corresponding design values.

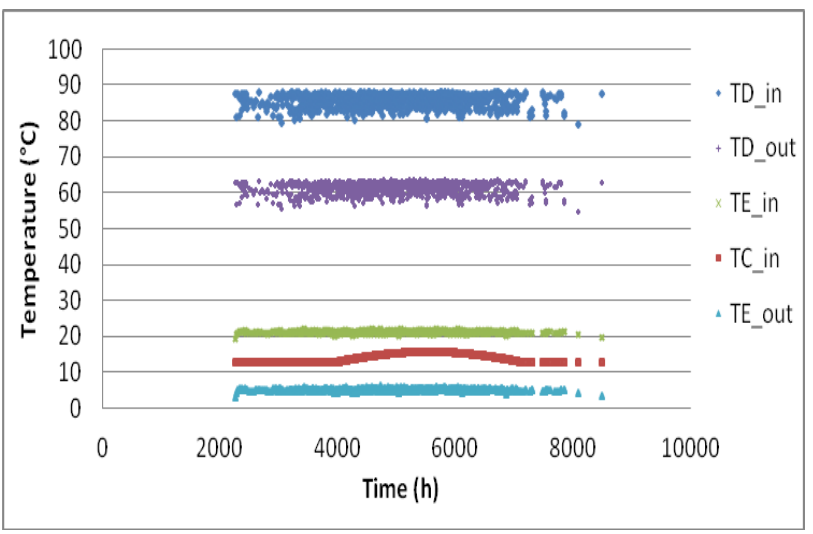

Fig. 5a Temperature of the external fluids of the absorption cooler for a typical Montreal meteorological year

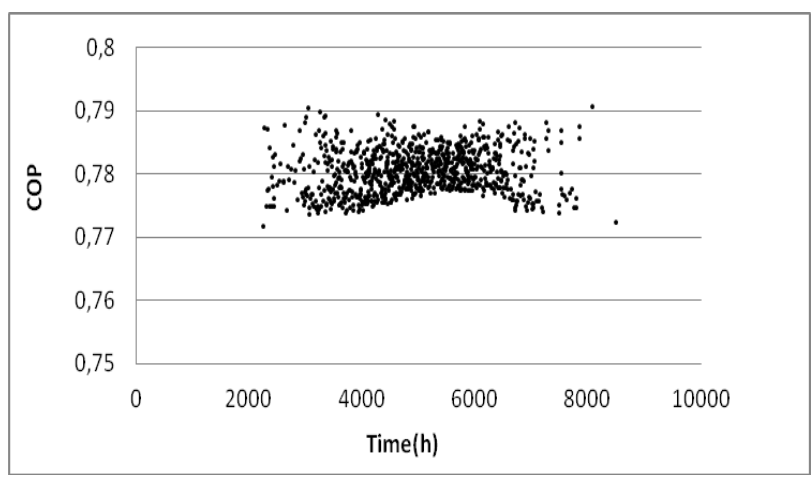

Fig. 5b Coefficient of Performance of the absorption cooler for a typical Montreal meteorological year

Figure 6 shows the monthly energy consumption of the trigeneration system and the way it is distributed among the different loads. Despite the cold winters experienced in Montreal (4428 heating degree-days) the highest energy consumption occurs during the hot-humid months of July and August followed by January. The lowest energy consumption occurs in October, November and April which require little heating and cooling. The losses due to incomplete recovery of the energy released by burning the fuel in the IC motor, thermal losses of the storage reservoirs and energy rejected by the absorption cooler are lowest in January-December (approximately $10 \%$ of the total) and highest in July-August (approximately $25 \%$ of the total); consequently the efficiency of the trigeneration system is approximately $90 \%$ and $75 \%$ respectively. Electricity generation is roughly constant at $35 \%$ of the total throughout the year. Domestic hot water uses between approximately $5 \%$ and $15 \%$ of the total with the high values occurring in April and October and the low in January and December. Heating represents almost $50 \%$ of the total in January and December while it is essentially zero during the four warmest months (June to September). Finally cooling peaks at about $35 \%$ of the total in July and is zero during the four coldest months (December to March).

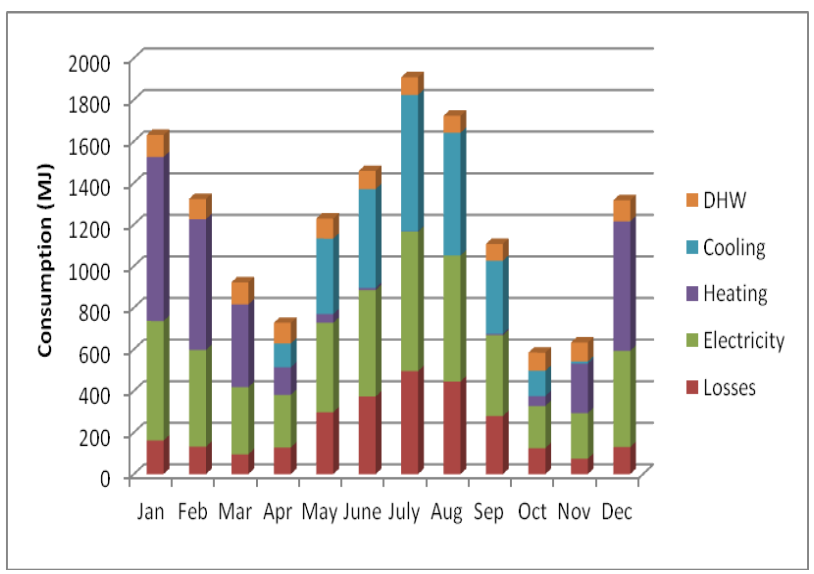

Fig. 6 Monthly energy consumption of the trigeneration system

It should be noted that these results were obtained for heating and cooling set points equal to $21^{\circ} \mathrm{C}$ and $25^{\circ} \mathrm{C}$ respectively. The lowest and highest calculated temperatures for any of the 52 heated/cooled zones of the MURB are $19.8^{\circ} \mathrm{C}$ and $26.8^{\circ} \mathrm{C}$ respectively. However, 
more than $98 \%$ of the temperatures are above $20.3^{\circ} \mathrm{C}$ in winter and below $25.1^{\circ} \mathrm{C}$ in summer. Therefore the previously presented performance of the trigeneration system is not obtained at the expense of the comfort of the occupants.

The energy consumption of this trigeneration system was also compared with corresponding values of traditional schemes (central power plants supplying electricity to the MURB for lights, appliances, air conditioning, etc. plus local natural gas fired furnaces for space and DHW heating). For these comparisons two traditional schemes, representing current (BAU = business as usual) and advanced (BAT $=$ best available technology) systems, were considered. They are characterized by the efficiency for the following three energy conversion processes: natural gas to electricity, natural gas to heat (space heating and DHW) and natural gas to air conditioning. The assumed respective values are $0.35,0.8,1.225$ for BAU and $0.55,0.9,3.85$ for BAT. Figure 7 compares the monthly energy consumption of the trigeneration system with the corresponding values for the BAU and BAT schemes. It shows that the trigeneration system outperforms BAU throughout the year. The reduction of energy consumption is particularly high during the coldest months during which the trigeneration system is also better than the BAT scheme. On the other hand, the BAT scheme is more efficient than the trigeneration system during the warm months due to the superior COP of the compressor refrigeration units over the absorption coolers.

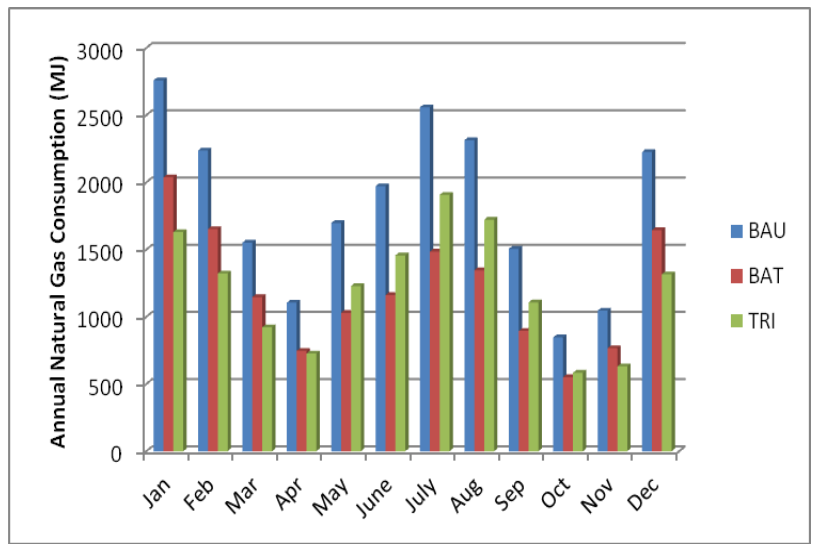

Fig. 7 Comparison of monthly energy consumption in Montreal with three different schemes

Figure 8 compares the annual natural gas consumption of the trigeneration system with those of the BAU and BAT systems at three Canadian cities. With respect to Montreal, Toronto is warmer and more humid while Edmonton is colder and drier. Thus the calculated heating and cooling loads for the MURB under consideration are respectively 2305 and 2726 GJ for Toronto, 4049 and 2048 GJ for Edmonton, 2915 and 2681 GJ for Montreal. Figure 8 shows that the trigeneration system outperforms the BAU scheme for all climates. Compared to the BAT scheme the primary energy consumption of the trigeneration scheme is essentially the same in Montreal, slightly worse in Toronto which requires more cooling and less heating, and slightly better in Edmonton which requires less cooling and more heating. The differences between the energy consumption of the trigeneration system and BAT scheme are not significant in view of the assumptions incorporated in the present calculations while those between the trigeneration system and BAU scheme are important.

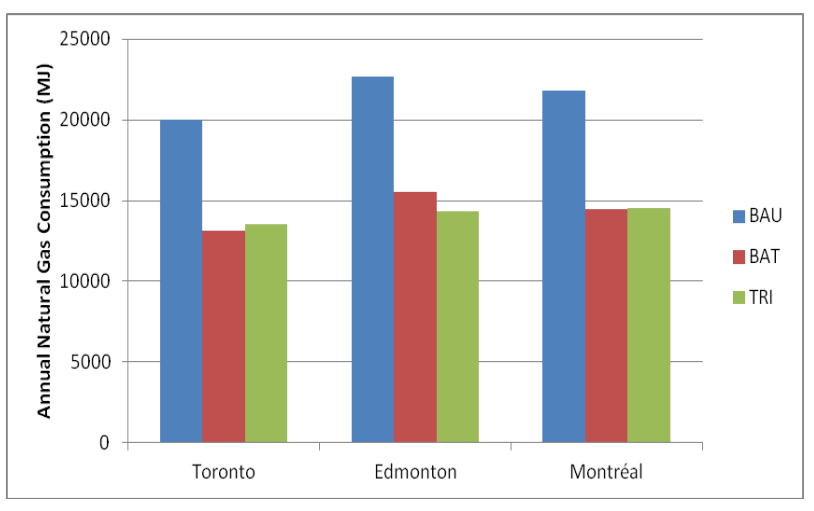

Fig. 8 Comparison of the yearly energy consumption at three Canadian cities

\section{Conclusion}

The present study developed a realistic model of an absorption cooler which was used to choose the design variables of such a machine fed by the waste heat of an internal combustion cogeneration unit. This model of the absorption cooler and a simplified model of the cogeneration unit were then coupled with the TRNSYS model of a 13 storey multi-unit residential building and the off-design performance of this complex system was evaluated for typical yearly climatic conditions.

The main results are:

- The absorption cooler operates with an almost constant COP $(0.78 \pm 0.01)$ and maintains all the zones of the building at comfortable temperatures;

- The efficiency of the trigeneration system varies between approximately $90 \%$ and $75 \%$ during the cold and hot months respectively;

- The primary energy consumption of the trigeneration system is high in summer and winter and low in spring and autumn;

- The trigeneration system maintains the temperature of the 52 heated/cooled zones of the building within the comfort region throughout the year;

- The primary energy consumption of the trigeneration system is significantly lower than that of average current central power systems and comparable to that of the best possible such systems;

- The primary energy savings achieved by the investigated trigeneration system are higher for locations having high heating loads and low cooling loads.

The presented energy analysis is not sufficient to establish the viability of the studied trigeneration system: economic and life-cycle analyses are required.

\section{Acknowledgement}

The financial support of the Natural Sciences and Engineering Research Council of Canada (NSERC) is gratefully acknowledged. 


\section{References}

[1] A. A. Manzela, S. M. Hanriot, L. Cabezas- Gómez and J. R. Sodré, "Using engine exhaust gas as energy source for an absorption refrigeration system", Applied Energy, Vol. 87, $\mathrm{n}^{\circ} 4$, pp. 1141-1148.

[2] L. Fu, X. L. Zhao, S. G. Zhang, Y. Jiang, H. Li and W. W. Yang, "Laboratory research on combined cooling, heating and power (CCHP) systems", Energy Conversion and Management, Vol. 50, $\mathrm{n}^{\circ}$ 4, pp. 977-982.

[3] L. Lin, Y. Wang, T. Al-Shemmeri, T. Ruxton, S. Turner, S. Zeng, J. Huang, Y. He, and X. Huang, "An experimental investigation of a household size trigeneration", Applied Thermal Engineering, Vol. 27, $\mathrm{n}^{\circ} 2-3$, pp. 576-585.

[4] J. C. Bruno, V. Ortega-López, and A. Coronas, "Integration of absorption cooling systems into micro gas turbine trigeneration systems using biogas: Case study of a sewage treatment plant", Applied Energy, Vol. 86, n 6, pp. 837847.

[5] G. Chicco and P. Mancarella, "Matrix modelling of smallscale trigeneration systems and application to operational optimization”, Energy, Vol. 34, n 3, pp. 261-273.

[6] M. A. Lozano, M. Carvalho and L. M. Serra, "Operational strategy and marginal costs in simple trigeneration systems", Energy, Vol. 34 n ${ }^{\circ} 11$, pp. 2001-2008.

[7] W. Jiang-Jiang, Z. Chun-Fa and J. You-Yin, "Multi-criteria analysis of combined cooling, heating and power systems in different climate zones in China", Applied Energy, Vol. 87, $\mathrm{n}^{\circ}$ 4, pp. 1247-1259.

[8] S. M. Lai and C. W. Hui, "Integration of trigeneration system and thermal storage under demand uncertainties", Applied Energy, Vol. 87, n 9, pp. 2868-2880.
[9] M. Kegel, R. Sunye, N. Galanis and M. A. Douglas, "Assessment of a sorption chiller driven by a cogeneration unit in a residential building" In Ressources naturelles Canada. http://canmetenergy-canmetenergie.nrcanrncan.gc.ca/eng/buildings_communities/buildings/heat_pu mps/publications/2011041.html, page consulted on 22 October 2011.

[10] University of Wisconsin, "TRaNsient SYstem Simulation" (Version 16), [Software], Retrieved from http://sel.me.wisc.edu/trnsys/

[11] COGENGREEN "La cogénération à l'huile végétale et au gaz naturel", http://www.cogengreen.com/cogeneration_belgique/cogen eration_technique.htm, page consulted on 23 May 2010.

[12] R. Zizzo, "Designing an optimal urban community mix for an aquifer thermal energy storage system", Applied sciences master thesis, Toronto University, Civil Engineering department, Toronto, Canada, 93 p.

[13] McGraw Hill, "Engineering Equation Solver" (Version 8.9.2.8), [Software], Retrieved from http://www.mhhe.com/engcs/mech/ees/

[14] B. Le Lostec, J. Millette and N. Galanis, "Finite time thermodynamics study and exergetic analysis of ammoniawater absorption systems", International Journal of Thermal Science, Vol. 49, $\mathrm{n}^{\circ}$ 7, pp. 1264-1276.

[15] U.S. Department of energy "Information resources" In EnergyPlus Energy Simulation Software. http://apps1.eere.energy.gov/buildings/energyplus/weather data_sources.cfm\#CWEC, page consulted on 18 March 2010. 